\title{
A Case Study of Severe Clear-Air Turbulence
}

\author{
By \\ Elmar R. Reiter \\ Colorado State University Research Foundation \\ Colorado State University \\ Fort Collins, Colorado
}

Scientific Report

Prepared for Navy Weather Research Facility under Contract

Number N 189 (188) 55120A.

March 1962
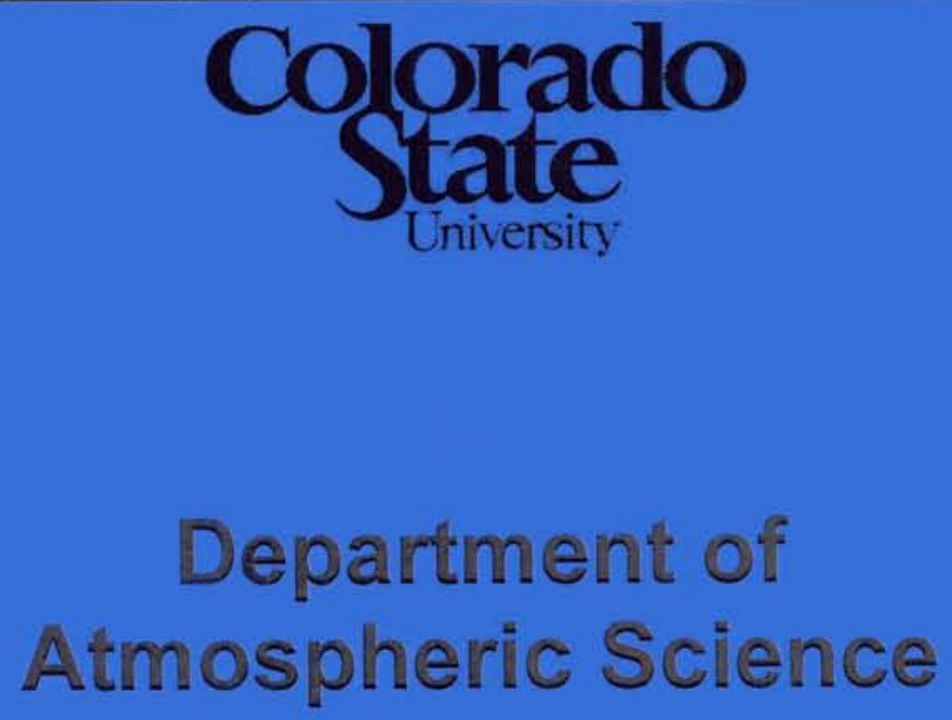

Paper No. 30 
ATMOSPHERIC SCIENCE TECHNICAL PAPER NO: 30

\author{
A CASE STUDY OF \\ SEVERE CLEAR-AIR TURBULENCE
}

by

Elmar R. Reiter

Scientific Report

Prepared for Navy Weather Research Facility under Contract Number N 189(188) $55120 \mathrm{~A}$

Colorado State University Research Foundation

Fort Collins, Colorado 
Scientific Report

A CASE STUDY OF SEVERE CLEAR-AIR TURBULENCE

by

Elmar R. Reiter

ABSTRACT

On January 19, 1961, 1816 MST (= January 20, 0116 GCT), a B-52 aircraft was lost in severe clear-air turbulence (CAT) over northwestern New Mexico. This report describes the weather conditions in the upper troposphere and lower stratosphere at the time of the accident. A working hypothesis on the formation of CAT proposed in previous papers is in good agreement with the data presented here.

\section{INT RODUCTION}

In several previous publications the author has expressed the hypothesis, that clear-air "turbulence" may have nothing at all to do with "turbulence" in a hydrodynamic sense (Reiter 1960, 1961a, 1962a, b). "Bumpiness in flight through clear air" may be caused by gravity waves, forming on stable interfaces. The flow conditions under such circumstances may be perfectly "laminar" in the terminology of hydrodynamics.

It has also been pointed out previously, that shallow stable and baroclinic layers in the atmosphere are favored by perturbations of meso-

scalar ( $10^{4}$ to $10^{5}$ horizontal meters) and micro-scal ar $\left(<10^{4}\right.$ horizontal meters) dimensions.

The evaluation of Project Jet Stream research flights has brought forth the result, that moderate and severe CAT seems to occur in the vicinity of a "trough" in the isentropic surfaces, which runs parallel to the jet axis and on its cyclonic side. This trough is produced by sinking motion, either 
in loco or upstream. It has been argued, that these sinking motions tend to stabilize the atmosphere, thus accounting for a preferred region of occurrence of the shallow stable layers mentioned earlier. Vertical wind shears, which usually exist in the neighborhood of these "isentrope troughs" are indicative of the baroclinicity, which, together with the stability, gives rise to small values of the modified Richardson criterion

$$
R_{i}^{*}=\frac{f^{2} \theta}{g \frac{\partial \theta}{\partial z}\left(\frac{\partial z}{\partial n}\right)_{\theta}^{2}}
$$

This criterion is obtained from the regular Richardson number $R_{i}=\frac{g}{\theta} \frac{\partial \theta}{\partial z} /\left(\frac{\partial V}{\partial z}\right)^{2}$ by substituting the vertical wind shear in the denominator by the thermal-wind equation (Radok and Clarke 1958). In this expression $f$ stands for the Coriolis parameter, $\theta$ for the potential temperature. The index $\theta$ indicates the differentiation along isentropic suriaces. $g$ is the acceleration of gravity and $\mathrm{V}$ the total wind speed. In the denominator of equation (1) the slope of the isobaric surfaces and the effect of changes of vertical wind shear with time have been neglected against the slope of isentropic surfaces.

Questionable as this substitution may be in view of the fact, that Richardson's criterion originally was derived under laboratory conditions, it seems to support some of the experimental findings during Project Jet Stream flights.

The Upper Flow Conditions Prior to the Accident.

According to an unpublished report by $\mathrm{H}$. Klieforth (1961), 'the B-52 was flying at $36,000 \mathrm{ft}$ pressure altitude on a magnetic heading of $310^{\circ}$ in the area of northwestern New Mexico.... The air was too turbulent to take celestial fixes so a climb through 40,000 ft was initiated. The pilot reported much haze and moderate to severe turbulence. While still climbing, the pilot lost control of the aircraft and, shortly after, ejected. The wings broke off - 
it was not clear whether this happened before or after the pilot ejected - and the plane crashed near Monticello, Utah, at about 1816 MST......"

Figure 1 shows the 250-mb winds and temperatures on 20 January 1961 , 00 GCT, i.e., approximately one hour prior to the plane crash. This particular isobaric level has been chosen for the analysis, because with its $33.999 \mathrm{ft}$ standard pressure altitude it was closest to the original flight level and because from previous experience this level proves to contain a temperature pattern which gives a fair indication of vertical motions near the tropopause level.

The isotach analysis of Figure 1 confirms the existence of a pronounced jet maximum over Arkansas (maximum speeds probably exceeding $70 \mathrm{mps}$ ). Another jet maximum with speeds in excess of $70 \mathrm{mps}$ is located of the New England coast. It is the former maximum which deserves our attention in conjunction with the reported plane crash.

The isotachs of Figure 1 outline three well-defined "jet fingers", i.e., belts of stronger winds spearated by areas of somewhat weaker winds. Such jet fingers are a rather common phenomenon in the entrance region of a well pronounced jet maximum. Little is known yet about the life history of such "fingers", whether they are remnants of previously present baroclinic zones, or whether they are produced by vertical circulations triggered off by the main jet stream.

In the present case, the main jet stream seems to be associated with the northernmost of the three branches. The wind data for Glasgow (768), Montana, are missing for levels between 250 and $150 \mathrm{mb}$. The soundings for Bismarck (764), N. D., Great Falls (775), Montana, and Lander (576), Wyoming, show their peak winds near the $300-\mathrm{mb}$ level, which is characteristic for a polar-front jet. The maximum speeds along the two southern jet branches occur at or above the $200-\mathrm{mb}$ level (cf. figs. 2 and 3 ), indicating a subtropical-type jet stream. 
Again it is typical for a weather situation like this, that polar front and subtropical jet streams merge in the tip of an elongated trough. While the axis of the polar-front jet possesses pronounced cyclonic curvature in the entrance region of the jet maximum, the subtropical jet axis curves anticyclonically.

The temperature analysis of Figure 1 shows several significant details, which shall be discussed here briefly. The tip of the trough over the Alleghenies is characterized by a pocket of warm temperatures at the $250-\mathrm{mb}$ level, so is the trough off the coast of Newfoundland. Obviously, in these two regions the $250-\mathrm{mb}$ surface lies above the tropopause. Considering the strong temperature gradients along streamlines (the latter may be inferred from the direction of the wind arrows plotted in fig. 1), extensive sinking motion will have to be expected near the jet stream and in areas upstream from these warm pockets.

Axes of relatively warm temperatures extend outward from these pockets (dashed-dotted lines in fig. 1), paralleling the jet axis. Specifically the warm axis north of the center branch of the triple jet stream in the entrainment region of the jet maximum deserves our attention. This axis is lacated about $80 \mathrm{n}$. miles south of Albuquerque and Amarillo. There is a quite pronounced stream-line convergence into this warm area. At the same time, the isotach pattern suggests, that the air particles undergo strong acceleration. It is worth mentioning, that Figure 1 does not reveal any excessive horizontal wind shears near the location of the plane crash. Although the air at flight level is entraining into a well-pronounced jet maximum, the upper winds at the time and location of the accident are rather light, barely reaching jet-stream speeds. The vertical wind shears, which may be estimated from the wind profiles shown in Figure 2, also are far from excessive. The turbulence criteria as given by J.J. George, (1961), therefore, do not seem to be applicable in this case. 
The vertical cross-section through the atmosphere between Grand Junction, Colorado, and Brownsville, Texas, which is reproduced in Figure 3, shows a broad baroclinic stable zone - the "jet stream front" if one wishes to adopt Endlich's and McLean's (1957) terminology -, whose upper surface is sloping down from $200 \mathrm{mb}$ to about $350 \mathrm{mb}$. It does not reach the ground anywhere in the vicinity of the jet-stream branches under investigation, which fact, again, would qualify these jet streams as belonging to the subtropical variety.

From this cross-section it seems, that the ill-fated B-52 penetrated into this stable layer from above some 60 or $70 \mathrm{n}$. miles north of Albuquerque. It was stated earlier, that the pilot decided to climb to $40,000 \mathrm{ft}$. As can be seen from the cross-section of Figure 3, this maneuver would not have improved conditions materially, because the climbing aircraft would stay close to the interface between "jet-stream front" and warm air. As has been mentioned in the introduction, such interfaces usually offer favorable conditions for the generation of gravity waves whose wave lengths are of the order of magnitude required for CAT, especially under the present conditions of vertical wind shear, although they may still be below George's threshold values.

The haze which the pilot observed in all probability also was associated with this stable and baroclinic zone.

In Figure 4 the soundings taken at Grand Junction and Albuquerque on January 20, 1961, at 00 GCT have been entered. (The figure presents a "Skew T, $\log \mathrm{p}$ " diagram of the U.S. Air Force.) We notice, that the bottom surface of the stable layer mentioned above lies very nearly on the same dry adiabate $\left(\mathrm{ca} .51^{\circ} \mathrm{C}\right)$ over both stations. The tropopause temperatures at the two stations, again, differ only by about $2^{\circ} \mathrm{C}$. There is, however, a marked difference in the potential temperatures of the upper boundary of the stable layer. While over Grand Junction it occurs at about $69^{\circ} \mathrm{C}$, over Albuquerque it has been coded on the standard pressure level $250 \mathrm{mb}$ with a potential 
temperature of only $60^{\circ} \mathrm{C}$. The latter station also shows no significant point reported between the standard levels of 250 and $200 \mathrm{mb}$. Between these two levels, however, the sounding reveals a rather peculiar, semistable lapse rate. Considering the research work of Danielsen (1959) on the leaf-like structure of the atmosphere, one may rather safely assume that a few very shallow, stable layers have been neglected between these two isobaric surfaces during the coding process, so that the error of the smoothed sounding curve in Figure 4 versus the actual atmospheric conditions still would be less than $2^{\circ} \mathrm{C}$, and the thickness of the layer $200 / 250 \mathrm{mb}$ would be represented correctly (cf. also Reiter 1961a). While this point could be proven beyond doubt only by means of the original radiosonde registrations, the reference to Danielsen's work may serve to illustrate the possibility of CAT occurrence due to internal gravity waves even before the aircraft penetrated into the "jet stream front". The setup for such shallow stable layers would be the more favorable in the area under consideration, if one considered the sinking motion which led to the formation of the "isentrope trough" pictured in Figure 1, and in Figure 3; in the latter it seems to coincide with the upper surface of the frontal zone. (cf. also Reiter 1962a).

The question remains whether the severe clear-air turbulence which caused the loss of the B-52 might have been associated with standing waves in the lee of the mountains. The terrain of New Mexico certainly would offer a favorable disposition towards the formation of such waves. Orographically generated perturbations may at times be detected at very high atmospheric levels (even in the ozonosphere) if thermal stratification and vertical wind profiles follow certain conditions which have been laid down in numerous theoretical papers (for literature cf. Reiter 1960, Alaka 1958). 
A parameter, which may be conveniently calculated from soundings and wind profiles, has been proposed by Lyra (1940):

$$
1^{2}=\frac{\frac{\partial T}{\partial z}+\Gamma}{\bar{T}} \frac{g}{\bar{V}^{2}}
$$

where $1^{2}$ is the square of the wave number, generated in the lee of the mountain, $\Gamma$ is the adiabatic temperature lapse rate, $g$ the acceleration of gravity, $\bar{V}$ the average wind speed and $\bar{T}$ the average temperature of the layer under consideration. Scorer (1949) also takes into account the curvature of the vertical wind profiles. His parameter has the form:

$$
1_{\text {Scorer }}^{2}=\frac{g}{\theta} \frac{\partial \theta}{\partial z}-\frac{1}{V} \frac{\partial^{2} V}{\partial z^{2}}
$$

Since, however, the. high level wind measurements are hardly of a quality to allow an accurate estimate of the second term on the right-hand side of this expression, we might just as well use Lyra's parameter for an estimate of lee-wave probability. According to Scorer's studies, such waves are forming only, if $1^{2}$ decreases with altitude. Maximum amplitudes will have to be expected at levels, where the vertical distribution of $1^{2}$ shows a maximum. The following table contains an evaluation of the parameter $1^{2}$ for the 00-GCT sounding on January 20, 1961, made at Albuquerque. From this table it may be seen, that $1^{2}$ decreases steadily between an elevation of $2300 \mathrm{~m}$ $(776 \mathrm{mb})$ and $9350 \mathrm{~m}(302 \mathrm{mb})$. The latter level corresponds to the lower boundary of the stable baroclinic zone, mentioned earlier. This zone itself especially its lower portion between 302 and $300 \mathrm{mb}$ - constitutes a secondary maximum of the parameter $I^{2}$. It, thus, would be favorable for the formation of lee-waves. Another secondary maximum, then, appears between 186 and $176 \mathrm{mb}$. 
TABLE

Computation of Lyra's parameter $1^{2}$ from the Albuquerque sounding, 20 January 1961, 00 GCT.

\begin{tabular}{|l|c|c|c|c|c|}
\hline $\mathrm{p}(\mathrm{mb})$ & $\mathrm{T}\left({ }^{\circ} \mathrm{C}\right)$ & $\mathrm{z}(\mathrm{m})$ & $\frac{\Delta \mathrm{T}}{\Delta \mathrm{z}}+0.996$ & $\bar{V}(\mathrm{~m} / \mathrm{sec})$ & $1^{2} \times 10^{-5}$ \\
\hline 845 & 3.3 & 1619 & -1.242 & 3 & 4.9301 \\
828 & -0.3 & 1780 & +0.111 & 3 & 0.4479 \\
776 & -4.9 & 2300 & +1.178 & 3 & 4.7672 \\
734 & -4.1 & 2740 & +2.354 & 8 & 1.3270 \\
700 & 1.0 & 3116 & +1.290 & 13 & 0.2748 \\
698 & 1.1 & 3150 & +0.495 & 14 & 0.09285 \\
500 & -14.0 & 5747 & +0.208 & 19 & 0.02214 \\
440 & -21.5 & 6700 & +0.197 & 20 & 0.01940 \\
400 & -27.1 & 7401 & +0.134 & 22 & 0.01139 \\
302 & -43.9 & 9350 & +0.804 & 23 & 0.06496 \\
300 & -44.0 & 9402 & +0.515 & 32 & 0.02176 \\
250 & -49.8 & 10613 & +0.322 & 47 & 0.00652 \\
200 & -59.4 & 12039 & +0.575 & 47 & 0.01198 \\
186 & -61.3 & 12490 & +2.115 & 41 & 0.05770 \\
176 & -57.5 & 12830 & +0.629 & 33 & 0.02646 \\
150 & -61.2 & 13840 & +0.676 & 30 & 0.03543 \\
100 & -69.1 & 16314 & & & \\
& & & & & \\
\hline
\end{tabular}


From Scorer's theory we have to expect maximum wave amplitudes, and therefore maximum hazard of CAT, in stable layers, a result which only corroborates what has been said earlier about these layers.

The existence of lee-waves in the general area of the B-52 flight is confirmed by observations of lenticular altocumulus clouds over several mountain stations, including Green River, Utah, Winslow, Arizona, and Albuquerque, New Mexico. (Klieforth 1961). Although these cloud forms have a length which exceeds the CAT wave lengths by at least one order of magnitude, orographically caused perturbations usually trigger off a whole "spectrum" of wave lengths, of which the lenticular clouds manifest only a small sector. Cloud observations over the Colorado area (Reiter 1962b) revealed a smallscale structure in the order of $10^{2}$ to $10^{3}$ meters of wave length frequently superimposed upon these standing lee wave formations, which would help to explain the frequent association of CAT with standing lee-waves.

\section{CONCLUSIONS}

While a "post mortem" study of CAT occurrence always leaves us with the advantage of a large supply of facts which are not available to the forecaster when he is pressed for his opinion, we may, nevertheless, draw several conclusions from the present study, which may lend themselves to operational application.

1, Strong horizontal and vertical wind shears seem to be neither a necessary nor a sufficient condition for moderate to severe CAT.

2. CAT over mountains as well as over the plains seems to be most frequently associated with stable and baroclinic layers in the atmosphere. The temperature field, therefore, should enter into CAT forecasting procedures.

3. The vicinity of warm "tongues" on upper-level charts (especially the 250-mb chart) seems to be favorable for the occurrence of moderate and severe CAT, probably due to the stabilizing effect of sinking motions in this area. 
Strong horizontal temperature gradients on the sides of these warm tongues indicate the presence of sloping stable layers, and should, therefore, be considered carefully in CAT forecasts. Maximum horizontal temperature gradients will be encountered on the north side of these warm tongues, when the stable layer is intercepted at a tropospheric level (as is the case over New Mexico under the conditions presented in fig, 1); it will be on the south side of the warm tongue, when the pressure level under consideration (e.g. $250 \mathrm{mb}$ ) penetrates into the stratosphere (e.g. over the New England coast in fig. 1). While in the first case moderate to severe CAT should be expected in the warm tongue and north of it, in the latter case the CAT cases should be expected in and slightly to the south of the warm tongue.

4. When taking evasive in-flight measures in order to get out of a CAT zone, one should bear in mind the orientation of the stable layers, with which this CAT is likely to be associated: Flying from the anticyclonic towards the cyclonic side of a jet stream at a tropospheric flight level, one should be out of the CAT zone faster by descending. Increasing the flight altitude might only lead the aircraft along one of these interfaces, without much improvement of the turbulent conditions, unless, of course, the climbing is done rapidly. For a flight conducted above the level of maximum wind, and cutting into the stratosphere, the stable layers should be expected to slope downward towards the north. Thus, an increase of pressure altitude would be an advisable maneuver, when going from the anticyclonic towards the cyclonic side of a jet stream. For flights in the opposite direction, the evasive maneuvers would have to be reversed, of course. For flights paralleling the jet stream, usually a change of altitude in either direction of about $2000 \mathrm{ft}$ will suffice to steer the aircraft out of a CAT layer in most cases.

While these recommendations do not constitute a cut-and-dried procedure for CAT avoidance, they may help the pilot as well as the forecaster to take advantage of the physical setup of the atmosphere in CAT areas. 
5. To stay clear of stable layers will be of particular importance in mountainous terrain, where perturbations which sustain - or even amplify themselves - on interfaces may be supplied in abundance by orographic influences. These perturbations may not only be of the order of wave lengths characteristic for lee-waves, but may range all the way down into the CAT "spectrum" (cf. Reiter 1962b).

It would be in the interest of air safety of military and civilian airborne operations:

a) if greatest care were taken in observing and coding the vertical temperature and wind distribution at radiosonde stations near mountain ranges;

b) if parameters indicating the lee-wave formation (such as Lyra's or Scorer's parameters) were computed on a routine basis for such stations;

c) if altitude ranges suspected of large wave amplitudes according to computations under item b) were either closed for air traffic altogether, or opened only with specific instructions for evasive measures, should moderate or severe turbulence be encountered. 


\section{LITERATURE REFERENCES}

Danielsen, E. F., 1959: The laminar structure of the atmosphere and its relation to the concept of a tropopause. Archiv. Meteo. Geoph. Bioklim., Ser. A. 11(3):293-332.

Alaka, M. A., 1958: Aviation aspects of mountain waves. World Meteor. Organiz., No. 68. TP. 26.

Endlich, R. M., and G. S. McLean, 1957: The structure of the jet stream core. Journ. Meteorol. 14: 543-552.

George, J. J., 1961: Prediction of clear air turbulence. Shell Aviation News, No. 273.

Radok, U., and R. H. Clarke, 1958: Some features of the subtropical jet stream. Beitr. Phys. d. fr. Atmosph. 31(1/2):89-108.

Reiter, E. R., 1960: Turbulenz im wolkenfreien Raum (Clear-Air Turbulence). Berichte d. Deutsch. Wetterdienstes Nr. 61.

Reiter, E. R., 1961a: Meteorologie der Strahlstroeme (Jet Streams). 473 pp. , Springer-Verlag, Wien.

Reiter, E. R., 1961b: The detailed structure of the wind field near the jet stream. Journ. Meteorol. 18(1):9-30.

Reiter, E. R., 1962a: Die vertikale Struktur des Strahlstromkernes aus Forschungsfluegen des Project Jet Stream. Berichte d. Deutsch. Wetterdienstes, Nr. 80.

Reiter, E. R., 1962b, On the nature of clear-air turbulence (CAT). Scientif. Interim Report, Part II., for Navy Weather Research Facility, under Contract No. N 189(188)538-28A, C.S.U. Atmospheric Sci. Tech. Paper No. 28; 16-34. 


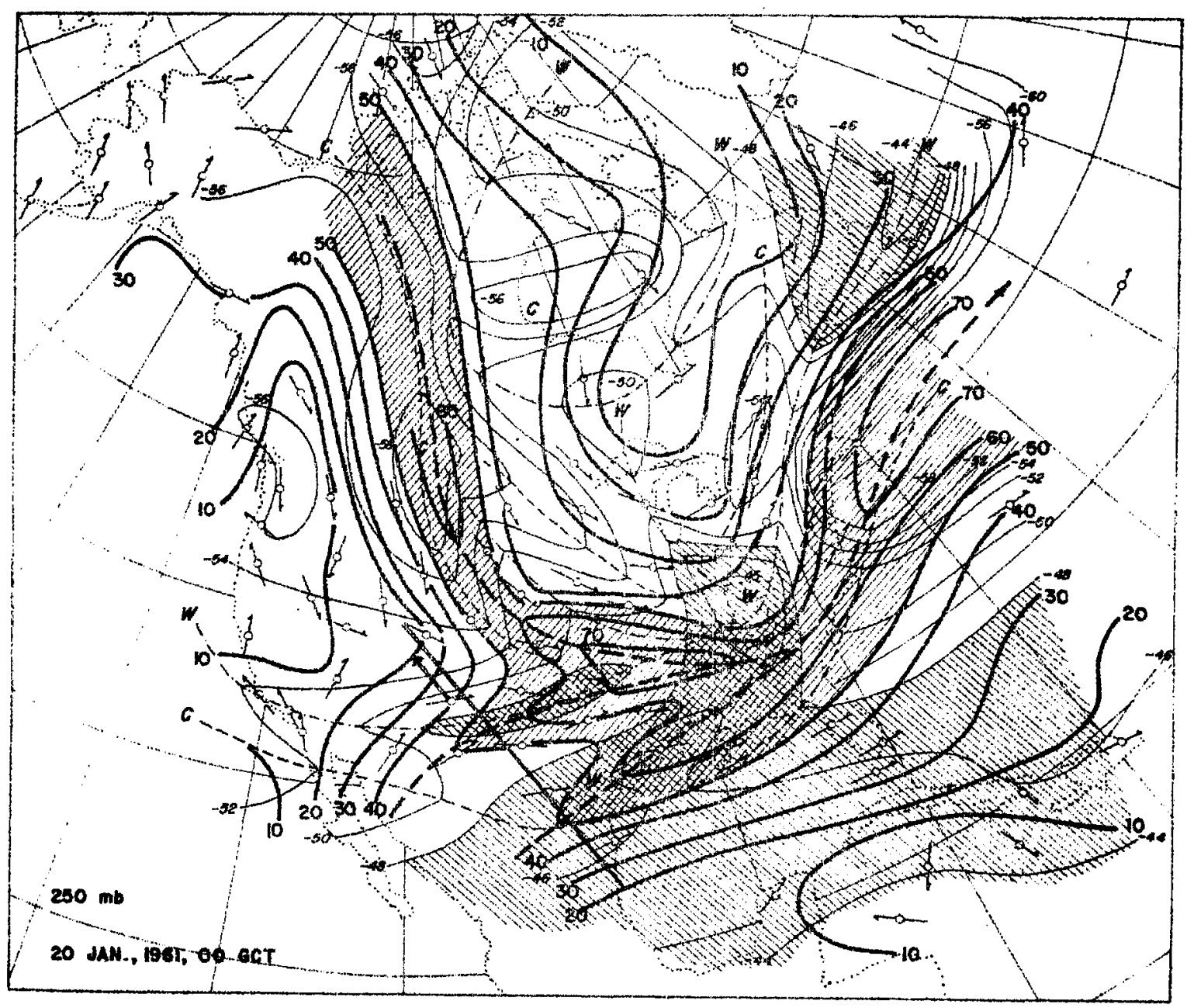

Fig. 1. 250-mb isotachs (mps, heavy solid lines) and isotherms $\left({ }^{\circ} \mathrm{C}\right.$, thin solid lines), 20 January $1961,00 \mathrm{GCT}$. Jet axes are indicated by heavy dashed lines, axes of cold areas by thin dashed lines and letuer $C$, axes of warm areas by thin dashed-dotted lines and letter $W$. Areas with wind speeds exceeding $50 \mathrm{mps}$ and with temperatures higher than $-48^{\circ} \mathrm{C}$ have been shaded. The position of the cross-section of Figure 2 is rarked by a thin double line, the fight track of the $B-52$ aircraft by a thin double line with an arrow. 


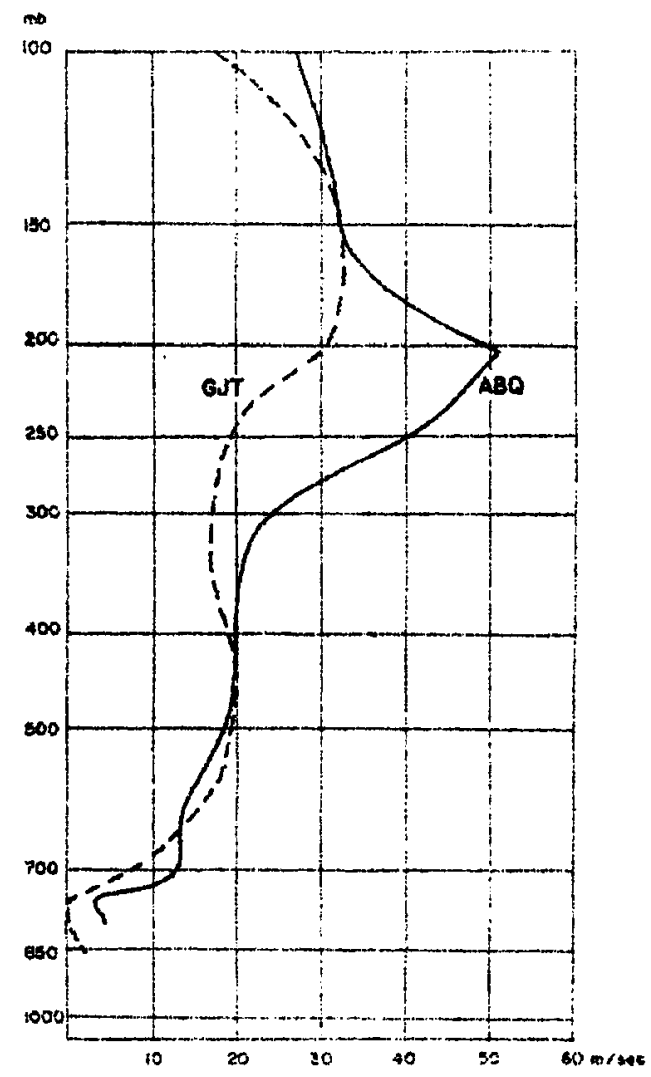

Fig. 2. Vertical wind profiles (mps), Grand Junction (GJT, dashed), Colorado, and Albuquerque (ABQ, solid line), New Mexico, 20 January 1961,00 GCT. 


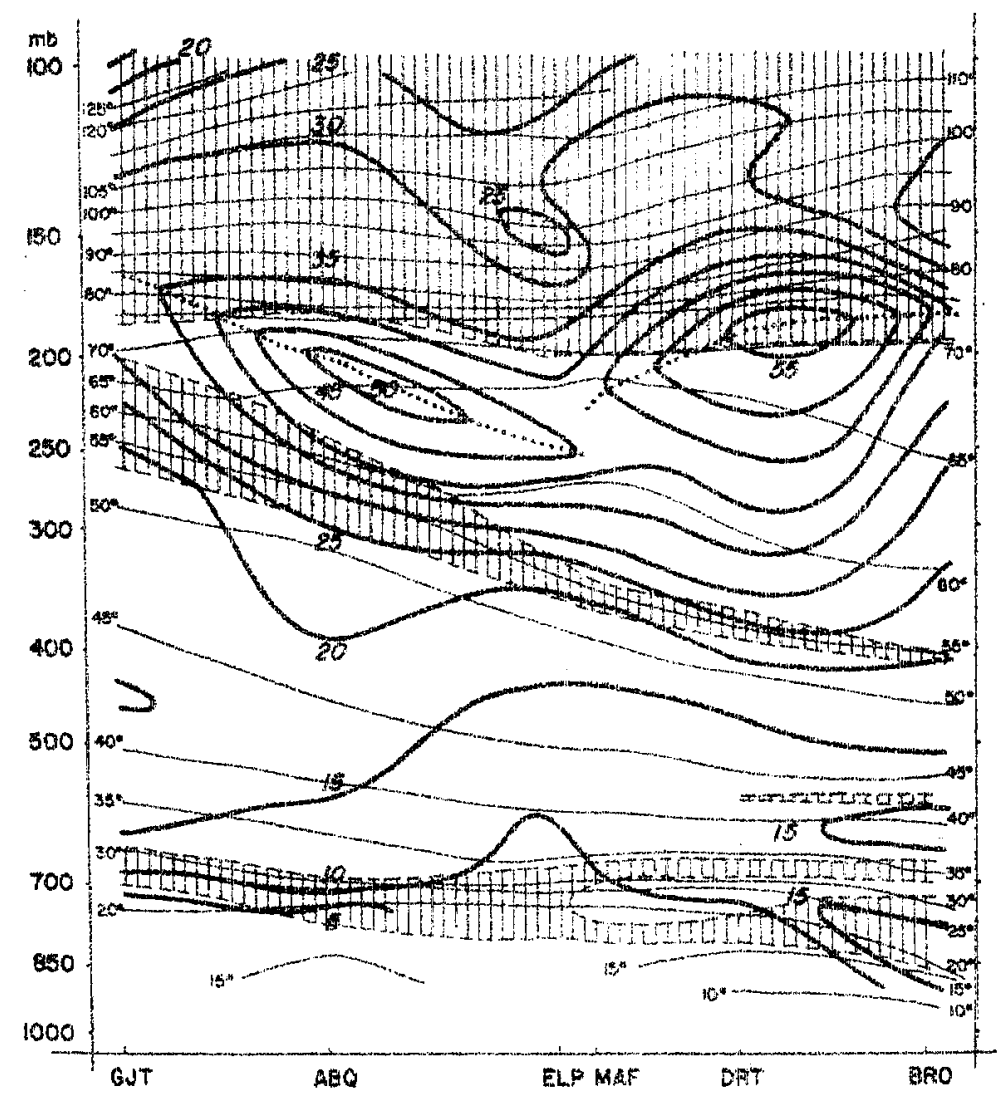

Fig. 3. Vertical cross-section through the atmosphere between Grand Jurction (GJT), Colorado, and Brownsille (BRO), Texas, on 20 January $1961,00 \mathrm{GCr}$. Heavy solid lines are isotachs (mps), thin solid lines are isotherms of potential temperature $\left({ }^{0} \mathrm{C}\right)$. Dotted: Level of maximum wind. Dashed: Boundares of stable layers and tropopause. Stable layers are furthermore indicated by shading. 


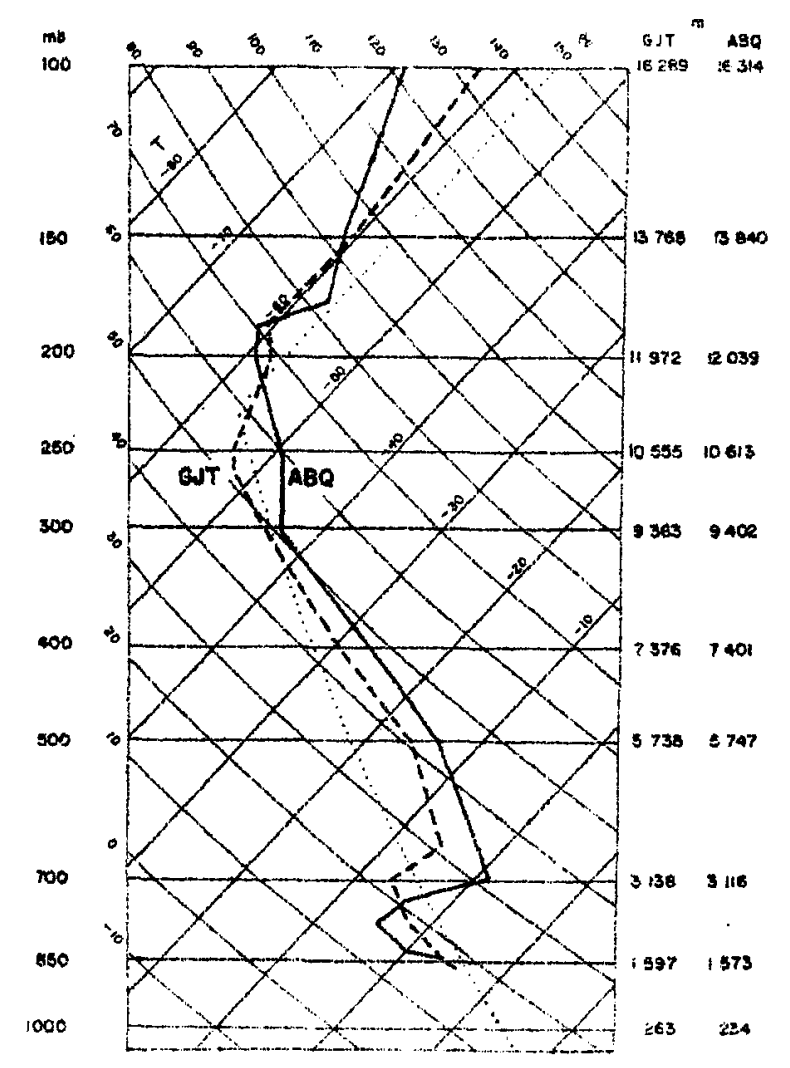

Fig. 4. Soundings of 20 January, 1961, 00 GCT, at Grand Junction (GJT, dashed), Colorado, and Albuquerque (ABQ, solid line), New Mexico, in a U.S. Air Force Skew T, log p diagram. Straight lines slanting from lower left to upper right are isotherms $\left({ }^{\circ} \mathrm{C}\right)$ of actual temperature, curves slanting from upper left to lower right are dry adiabates $\left({ }^{\circ} \mathrm{C}\right)$. The U.S. Standard atmosphere is entered as a dotted line. The heights $(\mathrm{m})$ of standard isobaric surfaces at the two stations are indicated on the right margin of the diagram. 